\title{
Investigating the use and constraints associated with green outdoor environment at workplaces: what do the office employees in Kuala Lumpur say?
}

\begin{abstract}
Green outdoor environment (GOE) is a dynamic infrastructure to an urban area and part of the city's ecosystem. Although numerous studies have been carried out on GOE, there is still a lack of information on GOE and its relationship in term of usability by office employees. The objectives of the study are to investigate the usage and constraints associated with GOE at workplaces by office employees in the Kuala Lumpur CCZ. The survey was conducted in September 2018 until March 2019 where 326 respondents $(\mathrm{N}=326)$ were involved in this study. The survey findings show that GOE in the Kuala Lumpur CCZ was widely used and enjoyed by diverse groups. Nevertheless, the study found variations in the use, preferences and constraints faced by office employees in CCZ using GOE. The respondents relate their concerns about the location of GOE at workplaces in the Kuala Lumpur CCZ, accessibility, quality of the environment and other personal issues like hectic working hours and health issues. By determining the function of GOE, we can identify any potential of GOE in Malaysian context despite its small size and maximise the use of GOE in the Kuala Lumpur CCZ as an urban space that can provide green, healthy, inclusive, open and public spaces for the citizen of Kuala Lumpur.
\end{abstract}

Keyword: Urban green space use; Workplace greenery; Work- related stress; Office worker; Workers' health 